\title{
Dimethyl Sulphoxide Reduction by Micro-organisms
}

\author{
By S. H. ZINDER* AND T. D. BROCK \\ Department of Bacteriology, University of Wisconsin, \\ Madison, Wisconsin 53706, U.S.A.
}

(Received 12 July 1977)

\begin{abstract}
Dimethyl sulphoxide (DMSO) was reduced to dimethyl sulphide by a wide variety of microorganisms, including prokaryotes and eukaryotes, aerobes and anaerobes. Dimethyl sulphone was not reduced by any of the organisms tested. Cell-free extracts of Escherichia coli reduced DMSO using reduced pyridine nucleotides as electron donors. Activity was greater in anaerobically grown cells than in those grown aerobically. Two other sulphoxides, methionine sulphoxide and tetramethylene sulphoxide, substantially inhibited DMSO reduction by extracts. Mutants of $E$. coli, which were unable to reduce biotin sulphoxide to biotin, were tested for their ability to reduce DMSO in whole cells and extracts. These mutants were in four different gene loci, bis $A$ to bisD. DMSO reductase activity of the mutants was generally less than that of the wild-type strain, and activity depended upon the gene locus involved, the growth medium and the growth conditions. Only the bis $A$ mutant had very low activity under all conditions. All of the bis mutants were able to grow using methionine sulphoxide as a sulphur source, indicating that biotin sulphoxide and methionine sulphoxide are reduced by different enzyme systems. DMSO may be reduced by both of these enzyme systems.
\end{abstract}

\section{INTRODUCTION}

Dimethyl sulphoxide (DMSO) is a waste product of paper mills which has recently received attention because of its potential medicinal value as a solvent which can be used to pass drugs through lipid membranes (Leake, 1967). It is also a possible intermediate in the global sulphur cycle as an atmospheric oxidation product of dimethyl sulphide (DMS) (Lovelock, Maggs \& Rasmussen, 1972).

Sulphoxides are generally formed from sulphides by peroxidation (Snow, Finley \& Kohler, 1976). Biotin sulphoxide and methionine sulphoxide are common metabolites (Black et al., 1960; Melville, 1954; Sato et al., 1958), and their reduction to sulphides by micro-organisms has been shown (Cleary \& Dykhuizen, 1974; Sourkes \& Trano, 1953). Certain pesticides are highly toxic to mammals when in the sulphoxide form, and microbial reduction may serve to detoxify them (Alexander, 1974). DMSO reduction to DMS has been shown in the cat (Distefano \& Borgstedt, 1964), in the cow and other animals (Tiews et al., 1975) and in plants (Smale, Lasater \& Hunter, 1975). Ando et al. (1957) surveyed members of the Enterobacteriaceae and found that while all strains of Escherichia coli tested reduced DMSO, no strains of Shigella and only one out of 40 strains of Salmonella reduced it; they suggested that this reaction might be of diagnostic value.

Dykhuizen (1973) isolated several mutant strains, from a biotin-requiring parent strain of $E$. coli, which could not reduce biotin sulphoxide to biotin (bis). These mutants were in four gene loci, which were called bis $A$, bis $B$, bis $C$ and $b i s D$. Three of these genes, bis $A$, bis $B$

* Present address: Department of Earth and Space Sciences, University of California, Los Angeles, California 90024, U.S.A. 
and $b i s D$, mapped very close to nitrate reductase genes. Methionine-requiring mutants which also could not reduce biotin sulphoxide could grow using methionine sulphoxide instead of methionine, indicating that the enzyme systems for reducing biotin sulphoxide and methionine sulphoxide are different. Cleary \& Dykhuizen (1974) developed an enzyme assay for biotin sulphoxide reductase in cell-free extracts of $E$. coli, and demonstrated that the enzyme was present in the wild-type strain but not in any of the bis mutants.

In studies of the sulphur cycle, we found that DMSO was readily reduced to DMS by anaerobically incubated lake sediments and sewage sludge. To determine whether this reduction was biological, we surveyed cultures of several micro-organisms for DMSO reduction. We found that DMSO reduction was common in micro-organisms, and so went on to study the process more closely in $E$. coli using cell-free enzyme preparations and the mutants isolated by Dykhuizen (1973).

\section{METHODS}

Organisms. All cultures were obtained from the University of Wisconsin, Department of Bacteriology culture collection, except for Desulfovibrio sp., which we isolated from sewage sludge. Escherichia coli $\mathrm{K} 12$ Hfr Cavalli was obtained from Dr Martha Howe, Department of Bacteriology, University of Wisconsin. Mutants of $E$. coli $\mathrm{K} 12$ unable to reduce biotin sulphoxide (bis) were obtained from Dr A. del CampilloCampbell, Department of Microbiology, Stanford University, and are more fully described in Table 4.

Culture media. Mineral salts $\mathrm{W}$ consisted of $1.0 \mathrm{~g} \mathrm{NH}_{4} \mathrm{Cl}, 0.13 \mathrm{~g} \mathrm{MgSO}_{4}, 3.0 \mathrm{~g} \mathrm{KH}_{2} \mathrm{PO}_{4}$ and $6.0 \mathrm{~g} \mathrm{Na}_{2} \mathrm{HPO}_{4}$ per 1 distilled water. Escherichia coli $\mathrm{K} 12$ was grown on mineral salts $\mathrm{W}$ plus $4.0 \mathrm{~g}$ glucose $1^{-1}$. The bis mutants and their parent strain were grown on GCAA medium, consisting of mineral salts $\mathrm{W}$, plus $4.0 \mathrm{~g}$ glucose $\mathrm{1}^{-1}, 1.0 \mathrm{~g}$ Difco Casamino acids $\mathrm{1}^{-1}$ and $10^{-2} \mu \mathrm{g}$ biotin $\mathrm{ml}^{-1}$. TYEG medium consisted of $5.0 \mathrm{~g}$ Difco Bactotryptone, $5.0 \mathrm{~g}$ Difco yeast extract and $5.0 \mathrm{~g}$ glucose per 1 distilled water. For growth of Clostridium butyricum, $0 \cdot 1 \mathrm{~g}$ sodium thioglycollate $^{-1}$ was added. Desulfovibrio $\mathrm{sp}$. was grown on a lactate/sulphate mineral salts medium described elsewhere (Zinder \& Brock, 1978). All cultures were incubated at $30^{\circ} \mathrm{C}$.

Gas chromatographic analysis of dimethyl sulphide. Dimethyl sulphide and other volatile sulphur compounds were measured using a Packard 419 gas chromatograph, fitted with a flame photometric detector. This detector is very sensitive to, and specific for sulphur compounds. The column used was similar to that of Stevens et al. (1971). The operating conditions were those described by Banwart \& Bremner (1974). Dimethyl sulphide could also be identified readily by its strong characteristic odour.

DMSO reduction by laboratory cultures. To $10 \mathrm{ml}$ TYEG medium sterilized in a $40 \mathrm{ml}$ serum vial, sterile DMSO (sterilized by passage through a sterile $0.45 \mu \mathrm{m}$ Millipore filter) was added to a final concentration of $100 \mu \mathrm{g} \mathrm{ml}^{-1}$. After the medium had been inoculated, the vials were sealed with Teflon-coated rubber stoppers (Supelco). For anaerobic incubations, the headspace was gassed with sterile nitrogen purified by passage over heated copper filings. Cultures were incubated at $30^{\circ} \mathrm{C}$ for $24 \mathrm{~h}$, by which time they had all reached the stationary phase, and the headspace was then sampled and analysed for DMS by gas chromatography. Because DMS is insoluble in water, it passes rapidly and quantitatively into the headspace. Cultures of Desulfovibrio sp. were grown in anaerobic culture tubes on lactate/sulphate medium for $4 \mathrm{~d}$ at $30^{\circ} \mathrm{C}$.

$D M S O$ reduction by crude extracts of E. coli. The procedure was based on that described by Cleary \& Dykhuizen (1974) for biotin sulphoxide reduction. Cells were grown aerobically in shake flasks, and anaerobically in neoprene-stoppered bottles with nitrogen in the headspace. Early-stationary phase cells were harvested, washed three times, and resuspended in 1/200th the original volume of $50 \mathrm{~mm}$-potassium phosphate buffer, $\mathrm{pH} 7 \cdot 0$, containing $2.0 \mathrm{~mm}-2$-mercaptoethanol. The cells were broken in a French press at about $69 \mathrm{MPa}\left(10000 \mathrm{lbf} \mathrm{in}^{-2}\right)$, and the extract was then dialysed overnight against phosphate buffer.

For the DMSO reduction assay, $0.8 \mathrm{ml}$ of dialysed crude extract, containing $4 \mathrm{mg}$ protein (Lowry et al., 1951), was placed in a $7 \mathrm{ml}$ serum vial. The vial was gassed with nitrogen purified by passage over heated copper filings, and sealed with an all-Teflon Mininert valve (Precision Sampling Co., Baton Rouge, Louisiana, U.S.A.). After incubation for $15 \mathrm{~min}$ in a $30^{\circ} \mathrm{C}$ water bath, the reaction was started by adding $0.1 \mathrm{ml}$ of $5 \mathrm{~mm}$-NADH or $5 \mathrm{~mm}$-NADPH and $0.1 \mathrm{ml}$ of $10 \mathrm{~mm}$-DMSO in rapid succession. The reaction mixture was incubated for $15 \mathrm{~min}$ at $30^{\circ} \mathrm{C}$ and then a headspace sample was taken with a gas-tight syringe and analysed for DMS by gas chromatography. As previously stared, all DMS produced is found in the headspace.

Growth on methionine sulphoxide. For studies in which methionine sulphoxide was the sole sulphur source, mineral salts $\mathrm{W}$ was modified so that sulphate was replaced by chloride. Cells were grown in culture tubes containing the modified mineral salts $\mathrm{W}$ plus $20 \mathrm{~mm}$-sodium lactate and $10^{-2} \mu \mathrm{g}$ biotin ml-1. Growth was measured as absorbance at $600 \mathrm{~nm}$ using a Spectronic 20 spectrophotometer (Bausch and Lomb).

Chemicals. Dimethyl sulphoxide and dimethyl sulphide were purchased from Fisher Chemical Co., 
Table 1. Reduction of DMSO by various micro-organisms

Cultures $(10 \mathrm{ml})$ in TYEG growth medium containing $100 \mu \mathrm{g}$ DMSO ml-1 were incubated at $30^{\circ} \mathrm{C}$ for $24 \mathrm{~h}$ in $40 \mathrm{ml}$ serum vials sealed with Teflon-coated rubber stoppers. After incubation, DMS in the headspace was measured by gas chromatography. See Methods for full details.

$\begin{array}{lclc} & \begin{array}{c}\text { Percentage } \\ \text { of DMSO } \\ \text { reduced } \\ \text { to DMS }\end{array} & \text { Organism } & \begin{array}{c}\text { Percentage } \\ \text { of DMSO } \\ \text { reduced } \\ \text { to DMS }\end{array} \\ \text { Escherichia coli } & 18 \cdot 0 & \text { Bacillus subtilis } & 17 \cdot 0 \\ \text { Salmonella typhimurium } & 10 \cdot 5 & \text { Bacillus cereus } & 0 \cdot 5 \\ \text { Klebsiella pneumoniae } & 37 \cdot 0 & \text { Clostridium butyricum } & 0 \cdot 1 \\ \text { Proteus vulgaris } & 24 \cdot 0 & \text { Arthrobacter } \text { sp. } & 5 \cdot 0 \\ \text { Providencia alcalifaciens } & 26 \cdot 0 & \text { Desulfovibrio } \text { sp. } & 1 \cdot 1 \\ \text { Pseudomonas aeruginosa } & 27 \cdot 0 & \text { Aspergillus niger } & 3 \cdot 0 \\ \text { Staphylococcus aureus } & 0 \cdot 5 & \text { Saccharomyces cerevisiae } & 4 \cdot 5 \\ \text { Streptococcus faecalis } & 0 \cdot 2 & & \end{array}$

* Grown on lactate/sulphate medium for $4 \mathrm{~d}$.

Fairlawn, New Jersey, U.S.A. L-Methionine, L-methionine- $d l$-sulphoxide, dimethyl sulphone, NADH and NADPH were obtained from Sigma. The methionine sulphoxide was shown to be free from contaminating methionine by thin-layer chromatography. Tetramethylene sulphoxide was purchased from Aldrich Chemical Co., Milwaukee, Wisconsin, U.S.A.

\section{RESULTS}

\section{Survey of micro-organisms for DMSO reduction}

A great variety of micro-organisms, including both prokaryotes and eukaryotes, reduced DMSO to DMS when growing on a complex medium (Table 1). To ensure that the DMS observed was derived from DMSO, controls to which no DMSO was added were examined. The amounts of DMS (and other volatile sulphur compounds, such as hydrogen sulphide, methane thiol and dimethyl disulphide) found in the controls was several orders of magnitude lower than in cultures with DMSO, and were most likely derived from breakdown of sulphur-containing amino acids (Kadota \& Ishida, 1972). No volatile products other than DMS were formed from DMSO. Dimethyl sulphone was not reduced by any of the cultures.

Members of the Enterobacteriaceae and Pseudomonas aeruginosa and Bacillus subtilis caused the greatest DMSO reduction, while fermentative anaerobes, such as Streptococclis faecalis and Clostridium butyricum, reduced DMSO the least. Some DMSO was reduced by the Desulfovibrio sp. culture, but preliminary experiments have shown that DMSO and hydrogen sulphide react slowly to form DMS, so that the DMSO reduction observed may have been an artifact due to the great hydrogen sulphide production by Desulfovibrio. In other experiments (Zinder \& Brock, 1978), we found that this strain of Desulfovibrio sp. could not grow using DMSO as an electron acceptor.

\section{DMSO reduction by cell-free extracts of $E$. coli}

Since $E$. coli was among those organisms which substantially reduced DMSO, and because this organism is so well characterized, the enzymic reduction of DMSO to DMS was studied using crude extracts of $E$. coli $\mathrm{K} 12$ grown in glucose/mineral salts medium. DMSO was reduced by these cell-free extracts in the presence of reduced pyridine nucleotides (Table 2). Activity was greater with NADH than with NADPH. If neither NADH nor NADPH was added, no activity was detected. Anaerobically grown cells had greater activity than aerobically grown cells, and the presence of DMSO in the growth medium did not substantially induce activity in anaerobically grown cells. If the extract had been boiled for $10 \mathrm{~min}$, or if no extract was added, no activity was detected. 
Table 2. Reduction of DMSO by crude extracts of E. coli $\mathrm{K} 12$

Assay mixtures $(1 \mathrm{ml}$ ) contained extract (4 mg protein), $1 \mathrm{mM}$-DMSO and $0.5 \mathrm{~mm}-\mathrm{NADH}$ or $0.5 \mathrm{~mm}$-NADPH; they were incubated under nitrogen at $30^{\circ} \mathrm{C}$ for $15 \mathrm{~min}$.

$\begin{array}{llc}\text { Growth conditions } & \text { Electron donor } & \begin{array}{c}\text { DMS } \\ \text { produced } \\ \text { [ng (mg } \\ \text { protein) } \\ \text { min }^{-1} \text { ] }\end{array} \\ \text { Anaerobic } & \text { NADH } & 31 \\ \text { Anaerobic } & \text { NADPH } & 11 \\ \text { Anaerobic } & \text { None } & 0 \cdot 1 \\ \text { Anaerobic with } & \text { NADH } & 34 \cdot 5 \\ \text { 100 } \mu \text { g DMSO ml } \text { m }^{-1} & \text { NADH } & 12 \cdot 5 \\ \text { Aerobic } & \text { NADPH } & 9 \cdot 5 \\ \text { Aerobic } & \text { NADH } & 0 \cdot 1 \\ \text { Anaerobic } & & \\ \text { (boiled extract) } & \text { NADH } & 0 \\ \text { No extract } & \text { NADPH } & 0 \\ \text { No extract } & \end{array}$

Table 3. Inhibition of reduction of DMSO by crude extracts of E. coli $\mathrm{K} 12$ Conditions were as in Table 2.

Inhibitor
$\mathrm{Na}_{2} \mathrm{~S}_{2} \mathrm{O}_{3}(1 \mathrm{mM})$
$\mathrm{Na}_{2} \mathrm{SO}_{3}(1 \mathrm{~mm})$
Dimethyl sulphone $(1 \mathrm{~mm})$
Methionine sulphoxide $(1 \mathrm{~mm})$
Tetramethylene sulphoxide $(1 \mathrm{~mm})$
$\mathrm{NaNO}_{3}(1 \mathrm{~mm})$
$\mathrm{O}_{2}(0 \cdot 21 \mathrm{~atm})$
EDTA $(10 \mathrm{mM})$

Inhibition
$(\%)$
9
4
0
61
74
22
84
39

Inhibitors of DMSO reduction by cell-free extracts of $E$. coli

Various compounds were tested to determine whether they inhibited DMSO reduction by crude extracts of anaerobically grown $E$. coli (Table 3 ). Sodium thiosulphate, sodium sulphite and dimethyl sulphone had little effect when added at a concentration equimolar with DMSO. The DMSO analogues, methionine sulphoxide and tetramethylene sulphoxide, substantially inhibited DMSO reduction, most likely by competition for an enzyme binding site. Sodium nitrate inhibited DMSO reduction, perhaps by funnelling electrons away, and oxygen prevented DMSO reduction by rapidly oxidizing the NADH (as determined by decrease of $A_{340}$ ). EDTA partially inhibited DMSO reduction, indicating that a complexed metal ion is involved.

DMSO reduction by cultures of bis mutants of E. coli

Mutants of E. coli, isolated by Dykhuizen (1973), which were unable to reduce biotin sulphoxide to biotin, were tested for their ability to reduce DMSO to DMS when growing on a complex medium (TYEG medium) or on a more defined medium (GCAA medium), similar to the one used by Cleary \& Dykhuizen (1974). The effects of aerobic or anaerobic growth conditions in these media were also compared (Table 4).

In TYEG medium, the bis $C$ mutant reduced as much DMSO as the wild-type strain, under both aerobic and anaerobic growth conditions. The bis $A$, bis $B$ and bis $D$ mutants showed little activity when grown aerobically, but there was a substantial increase in DMSO reduction by the bis $B$ and bis $D$ mutants when grown anaerobically. When grown aerobically at $37^{\circ} \mathrm{C}$, the bisC mutant reduced $58 \%$ of the DMSO added, i.e. the same amount as at $30{ }^{\circ} \mathrm{C}$, indicating that it is not a temperature-sensitive mutant growing at the permissive temperature. 
Table 4. Reduction of DMSO by the wild type and bis mutants of E. coli grown on TYEG or GCAA medium

Conditions were as in Table 1. Results indicate the percentage of DMSO reduced to DMS.

\begin{tabular}{|c|c|c|c|c|c|}
\hline \multirow[b]{2}{*}{ Strain } & \multirow[b]{2}{*}{ Properties* } & \multicolumn{2}{|c|}{ TYEG $†$} & \multicolumn{2}{|c|}{ GCAA } \\
\hline & & Aerobic & Anaerobic & Aerobic & Anaerobic \\
\hline R $879(\mathrm{WT})$ & bio $A 24$ & 48 & 64 & $7 \cdot 2$ & 70 \\
\hline $\mathrm{R} 876($ bis $A)$ & bioC 18 chlE- bisAl8 & $0 \cdot 1$ & 0.3 & $0 \cdot 3$ & $0 \cdot 1$ \\
\hline $\mathrm{DD} 42($ bis $B)$ & bio $A 24$ bis $B$ & $0 \cdot 1$ & $4 \cdot 5$ & $1 \cdot 5$ & $9 \cdot 8$ \\
\hline DD133 (bisC) & bioA24 bisC32 & 58 & 88 & $7 \cdot 0$ & 74 \\
\hline DD39 (bisD) & bioA24 bis D21 chlG ${ }^{-}$ & $0 \cdot 1$ & 17 & 0.2 & $4 \cdot 0$ \\
\hline
\end{tabular}

* From Dykhuizen (1973): bio, requires biotin; bis, unable to reduce biotin sulphoxide; $\mathrm{chl}^{-}$, chlorate resistant (unable to reduce nitrate).

$\dagger$ Tryptone yeast extract glucose medium.

$\$$ Glucose casamino acids medium.

Table 5. Reduction of DMSO by crude extracts of the wild type and bis mutants of E. coli grown on GCAA medium

Conditions were as described in Table 2. Results are expressed as ng DMS produced $\min ^{-1}(\mathrm{mg} \text { protein })^{-1}$.

\begin{tabular}{|c|c|c|c|c|}
\hline \multirow[b]{2}{*}{ Strain } & \multicolumn{2}{|c|}{ Aerobic } & \multicolumn{2}{|c|}{ Anaerobic } \\
\hline & NADH & NADPH & $\mathrm{NADH}$ & NADPH \\
\hline R $879($ WT $)$ & $6 \cdot 3$ & $5 \cdot 5$ & 50 & 41 \\
\hline $\mathrm{R} 876($ bis $A)$ & $0 \cdot 8$ & $1 \cdot 0$ & $2 \cdot 3$ & ND \\
\hline DD42 (bis B) & $3 \cdot 7$ & $3 \cdot 9$ & 18 & ND \\
\hline DD133 (bisC) & $1 \cdot 8$ & $1 \cdot 3$ & 17 & ND \\
\hline DD39 (bisD) & $1 \cdot 6$ & $1 \cdot 6$ & $9 \cdot 0$ & ND \\
\hline
\end{tabular}

When grown aerobically in GCAA medium, the wild-type strain and the bisC mutant again showed similar activity, but reduced considerably less DMSO than in the richer TYEG medium. This may be a function of the lower growth yield in GCAA medium rather than lower specific activity. However, when grown anaerobically, they both reduced substantially more DMSO. The bisB and bisD mutants showed low activity when grown aerobically, but reduced more DMSO anaerobically, as in TYEG medium. Under all growth conditions tested, the bis $A$ mutant did not substantially reduce DMSO.

$D M S O$ reduction by crude extracts of bis mutants of $E$. coli

Crude extracts of the biotin sulphoxide mutants were assayed for DMSO reduction to see whether enzyme levels paralleled the reduction found in vivo. Cells were grown aerobically or anaerobically in GCAA medium, and reduction by extracts was assayed in the presence of NADH or NADPH. As in E. coli $\mathrm{K} 12$, there was greater activity in the wild-type strain grown anaerobically than aerobically (Table 5). The increase in activity was similar to that found in growth media. NADH was slightly more effective as an electron donor than NADPH. The bis A mutant showed low activity under all conditions, as it did in the growth medium, and the bisB and bis $D$ mutants showed an increase in activity when grown anaerobically, as they did in growth medium. The low activity of the bis $C$ mutant is enigmatic, since its in vivo activity was similar to that of the wild-type strain.

Growth on methionine sulphoxide by bis mutants of E. coli

The ability of the bis mutants to grow using methionine sulphoxide as a sole sulphur source was examined to ascertain whether biotin sulphoxide and methionine sulphoxide reduction are independent reactions. Growth using methionine sulphoxide implies reduc- 
Table 6. Ability of bis mutants to grow using methionine sulphoxide as a sulphur source

Sulphur sources were provided at $10 \mu \mathrm{g} \mathrm{S} \mathrm{ml}^{-1}$. Results indicate turbidities, expressed as $A_{600}$.

\begin{tabular}{lcccc} 
& \multicolumn{4}{c}{ Sulphur source } \\
Strain & None & L-Methionine & $\begin{array}{c}\text { L-Methionine } \\
\text { sulphoxide }\end{array}$ & Sulphate \\
R 879 (WT) & 0.07 & 0.31 & 0.29 & 0.90 \\
R 876 (bis $A)$ & 0.11 & 0.30 & 0.25 & ND \\
DD42 (bisB) & 0.06 & 0.32 & 0.31 & ND \\
DD133 (bis $C)$ & 0.11 & 0.31 & 0.33 & ND \\
DD39 (bis $D)$ & 0.10 & 0.32 & 0.32 & ND
\end{tabular}

ND, Not determined.

tion, since it is much more polar than methionine, and unlikely to be able to replace methionine in proteins.

Minimal growth occurred in sulphur-deficient medium (Table 6). Roberts et al. (1955) have determined that $10 \mu \mathrm{g} \mathrm{S} \mathrm{ml}^{-1}$ is sufficient for good growth of $E$. coli. All strains (with the possible exception of the bis $A$ mutant) grew as well using methionine sulphoxide $\left(10 \mu \mathrm{g} \mathrm{S} \mathrm{ml}^{-1}\right)$ as a sulphur source as with methionine. Thus, all the mutants possess the ability to reduce methionine sulphoxide suggesting that there are two separate reduction systems for the two sulphoxides. As described by Roberts et al. (1955), growth yields were lower using methionine than sulphate as a sulphur source. DMSO could not serve as a sulphur source for growth.

\section{DISCUSSION}

DMSO is reduced to DMS by a wide variety of micro-organisms, both prokaryotic and eukaryotic. It is of interest that the two fermentative anaerobes included in the survey reduced DMSO the least. Obviously, a more comprehensive survey would have to be done before general conclusions can be made. Zinder \& Brock (1978) have found that DMSO could be used as an electron acceptor for growth by a spiral organism, isolated from lake mud, and by Proteus vulgaris, but not by $E$. coli, Pseudomonas aeruginosa or Desulfovibrio sp. Although Ando et al. (1957) found that only one strain out of 40 Salmonella strains they tested reduced DMSO (as determined by formation of a precipitate with mercuric chloride), the one strain which we tested was able to reduce it significantly. Dimethyl sulphone was not reduced by any of the strains tested, which is not surprising since sulphones are very chemically and biochemically stable (Tonzetich, 1976). Dimethyl sulphone is a natural product, and humans excrete 4 to $11 \mathrm{mg}$ per day in their urine (Williams, Burstein \& Layne, 1966).

Escherichia coli has an enzyme system capable of reduction of DMSO to DMS using reduced pyridine nucleotides as electron donors. In vitro reduction is somewhat greater using NADH than NADPH. Anaerobically grown cells had greater activity than aerobically grown cells, and this could be due to either an increase in a pre-existing enzyme, or induction of a new one.

A reaction which is similar to DMSO reduction is the reduction of trimethylamine oxide by Salmonella typhimurium. Kim \& Chang (1974) have found that a mutant without nitrate reductase was unable to reduce it. Our mutant studies have not given such clear results. Mutants unable to reduce biotin sulphoxide showed varying ability to reduce DMSO, but less activity than the wild-type strain, indicating a relationship between biotin sulphoxide and DMSO reductions. The bisA mutant showed consistently low DMSO reduction activity, both in vivo and in vitro. This may be due to the loss of some general component used by many reductases, since this mutant is also deficient in nitrate reductase. It should be mentioned that growth of the bis $A$ and bis $D$ mutants often lagged behind that of the other strains, indicating that some useful function was lost. The bis $B$ and bis $D$ mutants showed 
increased DMSO reduction when grown anaerobically. It is not clear why the bisC mutant had identical activity with the wild-type strain in vivo, but less in vitro.

Although there appears to be some relationship between the system involved in the reduction of biotin sulphoxide and that which reduced DMSO, there are also some differences between them. Cleary \& Dykhuizen (1974) found that NADPH rather than NADH was the better donor for biotin sulphoxide reduction. Also, none of the aerobically grown mutant strains had any appreciable biotin sulphoxide reductase activity compared with the wildtype strain, whereas the mutants other than bis $A$ reduced up to $50 \%$ as much DMSO as did the wild-type strain

The mutants (with the possible exception of bis $A$ ) could grow on methionine sulphoxide, in agreement with the findings of Dykhuizen (1973). Methionine sulphoxide inhibited in vitro DMSO reduction, which suggests that there is a separate system for reducing methionine sulphoxide, which is also capable of DMSO reduction. DMSO has greater structural similarity with methionine sulphoxide than with biotin sulphoxide, although both enzyme systems may reduce it.

It is unlikely that DMSO reduction is of any physiological benefit to $E$. coli or the other organisms shown to reduce it. Evidence for this is that $E$. coli cannot use DMSO as an electron acceptor for growth or as a sulphur source. Also DMSO in the growth medium does not induce greater synthesis of the enzyme system which reduces it. The activity we have found may be due to non-specific reduction by an enzyme system meant to reduce some other, dissimilar substrate. More likely, DMSO reduction is due to the presence of separate enzyme systems which reduce biotin and methionine sulphoxides, both of which are natural metabolites. Snow et al. (1976) suggested that a substantiall portion of the methionine in foods is oxidized to the sulphoxide, and if this is so, it would be advantageous to an organism such as E. coli, living in the intestine, to reduce it. Methionine sulphoxide has a metabolic role in the absorption of methionine by the intestine (Sugawa, Akedo \& Suda, 1960 ) and in pectin formation in plant tissue (Sato et al., 1958), and it is quite possible that sulphoxides also play a role in microbial metabolism. Furthermore, if DMSO does play a role in the atmospheric sulphur cycle (Lovelock et al., 1972), it is likely that any DMSO reaching active microbial communities would be reduced to DMS.

This work was supported by a research contract from The Energy Research and Development Administration (COO-2161-39). The authors thank P. J. Kelman for assistance in some of the preliminary experiments.

\section{REFERENCES}

Alexander, M. (1974). Microbial formation of environmental pollutants. Advances in Applied Microbiology 18, 1-73.

Ando, H., Kumagai, M., Karashimada, T. \& IIDA, H. (1957). Diagnostic use of dimethylsulfoxide reduction test within Enterobacteriaceae. Japanese Journal of Microbiology 1, 335-338.

BanWart, W. L. \& Bremner, J. M. (1974). Gas chromatographic identification of sulfur gases in soil atmospheres. Soil Biology and Biochemistry 6, $113-115$

Black, S., Harte, E. M., Hudson, B. \& WartofSKY, L. (1960). A specific enzymatic reduction of L(-)-methionine sulfoxide, and a related nonspecific reduction of disulfides. Journal of Biological Chemistry 235, 2910-2916.

Cleary, P. P. \& Dykhuizen, D. (1974). Enzymatic reduction of D-biotin- $d$-sulfoxide with cell-free extracts of Escherichia coli. Biochemical and Biophysical Research Communications 56, 629-634.

Distefano, V. \& Borgstedt, H. H. (1964). Reduction of dimethylsulfoxide to dimethylsulfide in the cat. Science 144, 1137-1138.

22
DYKhuIZEN, D. (1973). Genetic analysis of the system that reduces biotin- $d$-sulfoxide in Escherichia coli. Journal of Bacteriology 115, 662-667.

Kadota, H. \& IsHIDA, Y. (1972). Production of volatile sulfur compounds by microorganisms. Annual Review of Microbiology 26, 127-138.

KIm, K. E. \& Chang, G. W. (1974). Trimethylamine oxide reduction by Salmonella. Canadian Journal of Microbiology 20, 1745-1748.

LEAKE, C. C. (1967). Introductory remarks. Annals of the New York Academy of Sciences 141, 1-3.

Lovelock, J. E., Maggs, R. J. \& Rasmussen, R. A. (1972). Atmospheric dimethyl sulphide and the natural sulphur cycle. Nature 237, 452-453.

Lowry, O. H., Rosebrough, N. J., Farr, A. L. \& RANDALL, R. J. (1951). Protein measurement with the Folin phenol reagent. Journal of Biological Chemistry 193, 265-275.

Melville, D. B. (1954). Biotin sulfoxide. Journal of Biological Chemistry 208, 495-501.

Roberts, R. B., Abelson, P. H., Cowie, D. B., Bolton, E. T. \& BRITTON, R. J. (1955). Studies of biosynthesis in Escherichia coli. Carnegie Institute M I C 105 
of Washington Publication 607.

Sato, C. S., Byerrum, R. U., Albersheim, P. \& BoNNER, J. (1958). Metabolism of methionine and pectin esterification in a plant tissue. Journal of Biological Chemistry 233, 138-141.

Smale, B. C., Lasater, M. J. \& Hunter, J. T. (1975). Fate and metabolism of DMSO in agricultural crops. Annals of the New York Academy of Sciences 243, 228-236.

Snow, J. T., Finley, J. W. \& Kohler, G. O. (1976). A kinetic study of bisulfite reduction of methionine sulphoxide to methionine. Journal of the Science of Food and Agriculture 27, 649-654.

Sourkes, T. L. \& Trano, Y. (1953). Reduction of methionine sulfoxides by Escherichia coli. Archives of Biochemistry and Biophysics 42, 321-326.

Stevens, R. K., Mulik, J. D., O'Keefe, A. E. \& Krost, K. J. (1971). Gas chromatography of reactive sulfur gases in air at the parts-perbillion level. Analytical Chemistry 43, 827-831.

Sugawa, R., Akedo, J. \& Suda, M. (1960). Intes- tinal absorption of amino acids. II. Isotopic studies on the amino acid absorption from the intestine using ${ }^{35} \mathrm{~S}$ DL-methionine and ${ }^{14} \mathrm{C}$ DLvaline. Journal of Biochemistry 47, 131-138.

Tiews, J., Scharrer, E., Harre, N. \& Flogel, L. (1975). Metabolism and excretion of dimethyl sulfoxide in cows and calves after topical and parenteral application. Annals of the New York Academy of Sciences 243, 139-150.

Tonzetich, J. (1976). Chromatographic separation of methionine, methionine sulphoxide, methionine sulphone, and their products of oral microbial metabolism. Analytical Biochemistry 73, 290-300.

Williams, K. I. H., Eurstein, S. H. \& Layne, D. S. (1966). Dimethyl sulfone: isolation from human urine. Archives of Biochemistry and Biophysics 113, 251-252.

ZINDER, S. H. \& ERock, T. D. (1978). Dimethyl sulphoxide as an electron acceptor for anaerobic growth. Archives of Microbiology (in the Press). 